\title{
Changes in Cardiovascular system among smokeless tobacco users attending tertiary care hospital in Andhra Pradesh, India
}

\author{
Annaji B ${ }^{1}$, Sreedevi P. ${ }^{2 *}$, Sudheer $\mathrm{K}^{3}$ \\ DOI: https://doi.org/10.17511/ijmrr.2020.i04.07 \\ 1 Annaji B, Assistant Professor, Department of General Medicine, Great Eastern Medical School and Hospital, Srikakulam, Andhra Pradesh, \\ India. \\ 2* Sreedevi P, Assistant Professor, Department of General Medicine, Great Eastern Medical School and Hospital, Srikakulam, Andhra \\ Pradesh, India. \\ 3 Sudheer K, Professor, Department of General Medicine, Great Eastern Medical School and Hospital, Srikakulam, Andhra Pradesh, India.
}

Background: Tobacco can be consumed as cigarettes and also as smokeless tobacco. Smokeless tobacco is a harmful tobacco product that contains over 3,000 chemicals, 7 including 28 known carcinogens (cancer-causing agents). Various forms of smokeless tobacco (mainly snuff and chewing tobacco) cause an immediate increase in heart rate and blood pressure. However, the relationship between smokeless tobacco uses on blood pressure remains unknown, especially in tertiary level hospitals. Our aim is to find out the smokeless tobacco use influence on cardiovascular parameters, for instance, pulse rate and blood pressure. Methods: This cross-sectional study was carried out to assess cardiovascular changes among adult male smokeless tobacco (ST) users. For this purpose, 50 male respondents were selected. The participants were selected from the medicine outpatient department of Great Eastern Medical School and Hospital, Srikakulam, Andhra Pradesh. Pulse rate and blood pressure were measured and ST uses behavior was assessed using self-reports. Statistical analysis was done by SPSS20. Results: In this study, the mean ( \pm SD) of pulse rate was $83.2 \pm 12.3$ beats/min. The mean $( \pm S D$ ) of systolic blood pressure was $158.72 \pm 24.84 \mathrm{~mm}$ of $\mathrm{Hg}$ and the mean ( $\pm S D$ ) of diastolic blood pressure was $98.78 \pm 9.87 \mathrm{~mm}$ of $\mathrm{Hg}$ in smokeless tobacco users. Conclusion: Mean systolic and diastolic blood pressures were higher in smokeless tobacco users in the tertiary level hospital. However, the mean pulse rate was within the normal range.

Keywords: Pulse rate, Smokeless tobacco, Systolic blood pressure, Diastolic blood pressure

Corresponding Author

Sreedevi P, Assistant Professor, Department of General Medicine, Great Eastern Medical School and Hospital, Srikakulam, Andhra Pradesh, India. Email: drsailajay@gmail.com
How to Cite this Article

Annaji B, Sreedevi P, Sudheer K. Changes in Cardiovascular system among smokeless tobacco users attending tertiary care hospital in Andhra Pradesh, India. Int J Med Res Rev. 2020;8(4):326330.

Available From

https://ijmrr.medresearch.in/index.php/ijmrr/article/ view/1209
To Browse

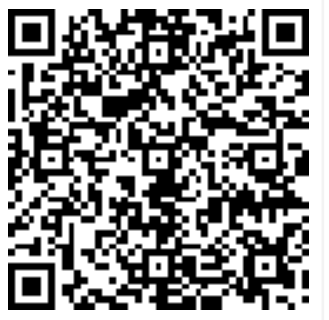

Manuscript Received 2020-07-25

Conflict of Interest No
Review Round 1 2020-08-12

Funding $\mathrm{Nil}$
Review Round 2 2020-08-22

Ethical Approval Yes
Review Round 3

Accepted 2020-08-28

Plagiarism X-checker $5 \%$

(C) 2020 by Annaji B, Sreedevi P, Sudheer K and Published by Siddharth Health Research and Social Welfare Society. This is an Open Access article licensed under a Creative Commons Attribution 4.0 International License https://creativecommons.org/licenses/by/4.0/ unported [CC BY 4.0]. 


\section{Introduction}

An estimated 600 million people worldwide, 300 million use smokeless tobacco [1]. Smokeless tobacco use is a significant part of the overall world tobacco problem. Nearly six million people die each year as a result of tobacco use, accounting for $12 \%$ of global adult mortality [2]. If current tobacco use patterns continue, it will cause some 10 million deaths each year by 2020 . Unlike cigarettes and other forms of tobacco, smokeless tobacco is consumed without combustion. Instead, it is placed in contact with mucous membranes in the mouth or nose, through which nicotine is absorbed into the body. The term smokeless tobacco refers to more than 30 different products, broadly categorized as 'spit tobacco' or 'chewing tobacco $[3,4]$. In North America, smokeless tobacco use typically consists of the oral use of snuff (moist or dry). In Central, South, and Southeast Asia, smokeless tobacco is usually chewed with another substance, such as ash, lime, cotton, sesame, or betel quid (a mixture of nut, lime, and leaves) [5]. Smokeless tobacco is a harmful tobacco product that contains over 3,000 chemicals, 7 including 28 known carcinogens (cancer-causing agents) [6]. Various forms of smokeless tobacco (mainly snuff and chewing tobacco) cause an immediate increase in heart rate and blood pressure [7]. Smokeless tobacco contains nicotine, and nicotine affects the heart. It causes the immediate effects of vasoconstriction, an elevated pulse rate, and blood pressure increases [8] and puts users at increased risk for stroke, coronary heart disease, peripheral vascular disease and cardiovascular death [9]. Blood pressure refers to the pressure inside the arteries. Hypertension means that the blood is exerting more pressure than in normal or healthy. Over time, this weakens and damages blood vessel walls. Hypertension may be caused by the thickening of the artery walls, resulting in narrowing and eventual blockage of the vessel [10]. The nicotine causes blood vessels to thin. Blood clots become more likely because of nicotine [11]. Nicotine raises blood pressure by constricting blood vessels. This occurs because nicotine directly stimulates the production of a hormone, epinephrine (also known as adrenaline), in the adrenal gland. Epinephrine raises blood pressure by constricting blood vessels [12]. It is important to note that some ST products, such as loose snuff and chewing tobacco, contain large amounts of sodium as part of the sodium bicarbonate alkaline buffer that is necessary to
Facilitate nicotine absorption; the sodium load (30 to 40 excess MEq sodium per day) could aggravate hypertension, as well as cardiac failure [13]. Furthermore, some ST products contain as a flavorant a large amount of licorice, which contains glycyrrhizinic acid that has mineralocorticoid activity, which can also aggravate hypertension and produce potassium wasting [14]. Smokeless Tobacco also contains more nicotine than cigarettes. That's what makes smokeless tobacco even more addicting than smoking cigarettes [15]. Smokeless tobacco is also a source of exposure to trace levels of some heavy metals, some of which, such as arsenic or manganese, may increase the risk of hypertension. It appears to be related to elevated homocysteine, a risk factor for heart disease $[16,17]$. Association of smokeless tobacco consumption with the occurrence of adverse cardiovascular events like myocardial infarction, stroke, and ischemic heart disease has been studied in detail in the western population.[18] There are limited prospective studies that assessed the role of smokeless tobacco on CVD outcomes or mortality. Further rigorous studies are needed to determine more clearly the cardiovascular risks potentially associated with smokeless tobacco use [19].

\section{Materials and Methods}

Study Design, Setting, and Duration: This Crosssectional study was conducted in the Department of Medicine, Great Eastern Medical School and Hospital from October 2018 to October 2019.

Exclusion criteria: Patients with diabetes, obesity, congestive heart failure, chronic obstructive lung disease, malignancies, secondary hypertension, renal failure, ischemic heart disease, peripheral vascular disease, gastrointestinal disease, systemic illness, and recent history of infection (within the last one month).

Inclusion Criteria: Subjects age over 20 years with smokeless tobacco usage were selected.

Ethics Approval: The study was conducted after getting approval from the Institutional Ethics Committee (IEC).

Sample Size and Data Collection: A total of 50 subjects who fulfilled the inclusion criteria were included in the study. All the subjects were explained about the aims and objectives of the study. The test procedures were briefed. Written consent was taken from the person concerned in a prescribed form. 
A detailed history of each subject including STU history was obtained by using a pre-tested questionnaire. Pulse rate was recorded and blood pressure was measured with a sphygmomanometer on both right and left arms while the patients were sitting after 10 minutes of resting. Measurements were made 3 times and the median of 3 measurements was obtained. The present study defined systolic hypertension as $\geq 140 \mathrm{mmHg}$, diastolic hypertension as $\geq 90 \mathrm{mmHg}$. All data were recorded in the data collection form.

Statistical Analysis: Statistical analyses were performed using SPSS software version 20. All continuous variables are expressed as mean \pm standard deviation; categorical variables are defined as percentages.

\section{Results}

In the present study of 50 smokeless tobacco users, the mean ( \pm SD) of age was $52.90 \pm 8.4$ years. Resided in Rural 45 (90\%), Semi-Urban 5 (10\%); Education level was primary $7(14 \%)$, secondary 13 $(26 \%)$, higher education $4(8 \%)$, illiterate, 26 $(52 \%)$; Occupation was private employee $6(12 \%)$, labour $19(38 \%)$, farmer $21(42 \%)$, business 4 $(8 \%)$; All (100\%) were regular user (Table 1$)$.

Table 1: Characteristics of the study population.

\begin{tabular}{|l|l|l|}
\hline \multicolumn{2}{|l|}{ Variables } & \multicolumn{1}{c|}{ Number (\%) } \\
\hline \multirow{3}{*}{ Residence Area } & Rural & $45(90 \%)$ \\
\cline { 2 - 3 } & Semi-Urban & $5(10 \%)$ \\
\hline \multirow{5}{*}{ Occupation } & Primary & $7(14 \%)$ \\
\cline { 2 - 3 } & Secondary & $13(26 \%)$ \\
\cline { 2 - 3 } & Higher Education & $4(8 \%)$ \\
\cline { 2 - 3 } & Illiterate & $26(52 \%)$ \\
\hline & Private Employee & $6(12 \%)$ \\
\cline { 2 - 3 } & Labour & $19(38 \%)$ \\
\cline { 2 - 3 } & Farmer & $21(42 \%)$ \\
\cline { 2 - 3 } & Business & $4(8 \%)$ \\
\hline
\end{tabular}

Table 2. Mean value of Pulse rate among Subjects

\begin{tabular}{|l|c|}
\hline Number of Smokeless Tobacco Users & Mean \pm SD \\
\hline 50 & $83.2 \pm 12.3$ beats $/ \mathrm{min}$ \\
\hline
\end{tabular}

The mean $( \pm S D)$ of pulse rate was $83.2 \pm 12.3$ beats/min.

Table 3. Mean values of Blood Pressure among Subjects

\begin{tabular}{|c|c|c|}
\hline Number of Smokeless & Systolic Blood & Diastolic Blood \\
Tobacco Users & Pressure (Mean \pm SD) & Pressure Mean \pm SD \\
\hline
\end{tabular}

\begin{tabular}{|l|l|l|}
\hline 50 & $158.72 \pm 24.84 \mathrm{~mm}$ of $\mathrm{Hg}$ & $98.78 \pm 9.87 \mathrm{~mm}$ of $\mathrm{Hg}$ \\
\hline
\end{tabular}

The mean $( \pm S D)$ of systolic blood pressure was $158.72 \pm 24.84 \mathrm{~mm}$ of $\mathrm{Hg}$ in smokeless tobacco users. And also, the mean ( $\pm S D$ ) of diastolic blood pressure was $98.78 \pm 9.87 \mathrm{~mm}$ of $\mathrm{Hg} .21$ (42\%) had hypertension and 29 (58\%) had normal blood pressure. 16 (32\%) had taken drugs for hypertension. Hypertension was controlled in $14(28 \%)$, uncontrolled in $7(14 \%) .18(36 \%)$ had a family history of high blood pressure.

\section{Discussion}

Smokeless tobacco affects the cardiovascular system and is associated with heart disease, stroke, and high blood pressure [20]. In the present study, the mean $( \pm S D)$ of pulse rate was $83.2 \pm 12.3$ beats/min and the mean ( $\pm S D$ ) of systolic blood pressure was $158.72 \pm 24.84 \mathrm{~mm}$ of $\mathrm{Hg}$ in smokeless tobacco users. The mean ( \pm SD) of diastolic blood pressure was $98.78 \pm 9.87 \mathrm{~mm}$ of $\mathrm{Hg}$ in them. The mean of systolic and diastolic blood pressure was higher than the normal level in smokeless tobacco users. Though, the mean pulse rate was within the normal range. One study states that smokeless tobacco use has a positive effect on cardiovascular risk factors in young physically fit Men [21]. Smokeless tobacco caused a clinically significant acute elevation of systolic blood pressure, diastolic blood pressure, or pulse. Smokeless tobacco was weakly associated with chronic hypertension. Smokeless tobacco may elevate blood pressure up to 90 minutes after use. Smokeless tobacco use should be considered a potential cause of sodium retention and poor blood pressure control because of its nicotine, sodium, and licorice content. Studies have established the acute effects of ST on heart rate (HR) and peripheral blood pressure. A single bout of ST elicits a transient increase in $H R$ and peripheral systolic (PSBP) and diastolic (PDBP) blood pressure in humans. One study suggests that ST causes a significant transient alteration in cardiovascular hemodynamics both peripherally and centrally. HR, central aortic blood pressure, and peripheral blood pressure values were all significantly elevated after one time ST use [22]. Hypertension was most common in smokeless tobacco users. These findings indicate that increased cardiovascular risk is also associated with the use of smokeless tobacco [23]. Hypertension is a strong predictor of future $\mathrm{CV}$ events such as MI and stroke and, therefore, determination of the impact of ST product use on the development of hypertension is important [24]. In one study at the 
15-year follow-up time point, and after adjustment for age and body mass index only, there was a modest increase in the relative risk for developing hypertension in current snuff users [25]. In another study (case-control), the prevalence of hypertension (systolic BP $\geq 170 /$ diastolic BP $\geq 95 \mathrm{~mm} \mathrm{Hg}$ ) was $35 \%$ in current snuff users. In this study, higher blood pressure in the smokeless tobacco users corroborates with findings in previous studies [26]. Association of smokeless tobacco consumption with the occurrence of adverse cardiovascular events like myocardial infarction, stroke, and ischemic heart disease has been studied in detail in the western population. Results from these studies paint a mixed picture with some showing increased incidence of these adverse events [27] while others showing no such association. Similarly, contradictory results have been seen in studies evaluating increased risk factors for cardiovascular diseases in the smokeless tobacco consuming population $[28,29]$.

\section{Limitations}

However, the present study has several limitations such as small sample size, not being able to extrapolate to all tobacco users due to exclusion criteria, not being able to generalize the result since the study subjects were from a single tertiary care center.

\section{Conclusion}

It is concluded from the present study that among smokeless tobacco users, the mean systolic and diastolic blood pressure were higher than normal. But the mean pulse rate was within the normal range.

\section{What does the study add to the existing knowledge}

The present study recommends, further large scale studies and long term follow-up to detect whether smokeless tobacco is associated with cardiovascular changes influencing pulse rate and blood pressure and also it should be included in the public health program to fight against tobacco use.

\section{Author's contribution}

Dr. B Annaji: Concept, study design

Dr. P Sreedevi: Data analysis

Dr. K Sudheer: Manuscript preparation

\section{Reference}

01. World Health Organization. WHO report on the global tobacco epidemic, 2011; Warning about the dangers of tobacco- Executive summary. Geneva- World Health Organization. 2011. Retrieved from [Article] [Crossref]

02. Ezzati M, Lopez AD. Regional, disease specific patterns of smoking-attributable mortality in 2000. Tob Control. 2004;13(4)388-395.

[Crossref]

03. World Health Organization (WHO). Impact of Tobacco-Related Illnesses in Bangladesh. New Delhi, India- World Health Organization, South East Asia Region. (2007).

[Crossref]

04. Gupta PC, Ray CS. Smokeless tobacco and health in India and South Asia. Respirol. 2003;8(4)419-431.

[Crossref]

05. Kuper H, Adam O, Buffett P. Tobacco use, cancer causation and public health impact. J Int Med. 2002;251(6)455-466.

[Crossref]

06. Benowitz NL. Pharmacology of Smokeless Tobacco Use- Nicotine Addiction and Smokeless Tobacco Health. Int Perspect. 1992(2)219.

[Crossref]

07. American Cancer Society. Smokeless tobaccoHighly addictive and no safer than smoking. American Cancer Society. 2020.

Available at from [Article] [Crossref]

08. Hergens MP, Lambe M, Pershagen G, Ye W. Risk of hypertension amongst Swedish male snuff users- a prospective study. J Intern Med. 2008;264(2)187-194.

[Crossref]

09. Knekt P, Alfthan G, Aromaa A, Heliövaara M, Marniemi J, Rissanen $H$, Reunanen $A$. Homocysteine and major coronary events- a prospective population study amongst women. J Intern Med. 2001;249(5)461-465.

[Crossref]

10. Asplund K. Smokeless tobacco and cardiovascular disease. Prog Cardiovasc Dis. 2003;45(5)383-394.

[Crossref] 
11. Benowitz NL. Sodium intake from smokeless tobacco. N Engl J Med. 1988;319(13)873-874. [Crossref]

12. Boucher BJ, Mannan N. Metabolic effects of the consumption of Areca catechu. Addict Biol. 2002; $7(1) 103-110$.

[Crossref]

13. Westman E. Does smokeless tobacco cause hypertension. Southern Med J. 1995;88(7)716720.

[Crossref]

14. Better Health Channel. Stroke prevention for high risk groups. Better Health Channel. 2020.

Available at [Article] [Crossref]

15. Heart Clinic. Smoking and High Blood Pressure. Eme Resou Hur wild. 2016.

Available at [Article] [Crossref]

16. Ilgenli TF, Akpinar $O$. Acute effects of smoking on right ventricular function. Swiss Med Weekly. 2007; 137;91.

[Crossref]

17. Valeriano J, Tucker $P$, Kattah J. An unusual cause of hypokalemic muscle weakness. Neurol. 1983;33(9)1242-1243.

[Crossref]

18. IARC. Working Group on the Evaluation of Carcinogenic Risks to Humans; World Health Organization, International Agency for Research on Cancer, Betel-quid and areca-nut chewing and some areca-nut-derived nitrosamines. Lyon, France- IARC Press. 2004.

[Crossref]

19. Wolk R, Shamsuzzaman AS, Svatikova A, Huyber CM, Huck C, Narkiewicz $K$, et al. Hemodynamic and autonomic effects of smokeless tobacco in healthy young men. J Am Coll Cardiol. 2005;45(6)910-914.

[Crossref]

20. Thom T, Haase N, Rosamond W, Howard VJ, Rumsfeld J, Manolio T, et al. Heart disease and stroke statistics-2006 update- a report from the American Heart Association Statistics Committee and Stroke Statistics Subcommittee. Circulation. 2006;113(6)e85-e151. [Crossref]
21. Ernster VL, Grady DS, Greene JC. Smokeless tobacco use and health effects among baseball players. JAMA. 1990;264(2)218-224.

[Crossref]

22. Hergens MP, Alfredsson PL, Bolinder G. Longterm use of Swedish moist snuff and the risk of myocardial infarction amongst men. J Intern Med. 2007;262(3)351-359.

[Crossref]

23. Benowitz NL, Porchet $H$, Sheiner $L$, Jacob III $P$. Nicotine absorption and cardiovascular effects with smokeless tobacco use- comparison with cigarettes and nicotine gum. Clin Pharmacol Ther. 1988;44(1)23-28.

[Crossref]

24. UK's Action on Smoking and Health (ASH). . . 1988;44(1)23-28.

[Crossref] [PubMed] [Google Scholar] [Crossref]

25. Haddock C K, Weg M V, DeBon M, Klesges RC, Talcott $G$ W, Lando $H$, et al. Evidence that smokeless tobacco use is a gateway for smoking initiation in youth adult males. Prevent Med. 2001;32(3)262-267.

[Crossref]

26. Siegel D, Benowitz N, Ernster VL, Grady DG, Hauck WW. Smokeless tobacco, cardiovascular risk factors, and nicotine and cotinine levels in professional baseball players. Am J Public Health. 1992;82(3)417-421.

[Crossref]

27. Bolinder GM, Ahlborg BO, Lindell JH. Use of smokeless tobacco- blood pressure elevation and other health hazards found in a large-scale population survey. J Intern Med. 1992; 232(4)327-34.

[Crossref]

28. Gupta BK, Kaushik A, Panwar RB, Chadda VS, Nayak KC, Singh VB, et al. Cardiovascular risk factors in tobacco-chewers: a controlled study. J Assoc Physicians India. 2007;55;27-31.

[Crossref]

29. Khurana M, Sharma D, Khandelwal PD. Lipid profile in smokers and tobacco chewers-a comparative study. J Assoc Physicians India. 2000;48(9)895-897.

[Crossref] 